\title{
DETERMINATION OF DYNAMIC CRITICAL RAINFALL BASED ON GEOMORPHOLOGICAL INSTANTANEOUS UNIT HYDROGRAPH AND RADIAL BASIS FUNCTION NEURAL NETWORK
}

\author{
WANG, W. S. - MA, X. X.* \\ College of Water Conservancy \& Environmental Engineering, Zhengzhou University, \\ Zhengzhou 450001, China \\ *Corresponding author \\ e-mail:maxx@zzu.edu.cn; phone: +86-136-1371-1818 \\ (Received $18^{\text {th }}$ Mar 2019; accepted $17^{\text {th }}$ May 2019)
}

\begin{abstract}
To disclose the formation mechanism of flash flood disaster, it is necessary to develop a dynamic critical rainfall model that considers all influencing factors. Targeting the Peihe River watershed in China's Henan Province, this paper designs a runoff convergence calculation plan based on the geomorphological instantaneous unit hydrograph (GIUH), and uses the plan to simulate 8 floods in the target watershed. The simulated results were close to the measured data. Next, the GIUH was adopted to predict the critical rainfalls of 16 floods in the target watershed. The radial basis function neural network (RBFNN) was selected to create a dynamic critical rainfall prediction model, with the preceding rainfall, cumulative rainfall and rainfall intensity as the inputs and the critical rainfall of each event as the output. The model was employed to predict the critical rainfalls of 6 historical floods. The results show that the prewarned critical rainfall reached the pass rates of $100 \%$ and $83.3 \%$, respectively, for the $1 \mathrm{~h}$ and $3 \mathrm{~h}$ periods. Hence, that the GIUH can ensure the calculation accuracy despite the lack of data in regions prone to flash flood; the RBFNN-based dynamic critical rainfall prediction model can effectively improve the accuracy of critical rainfall calculation and the flash flood prewarning.
\end{abstract}

Keywords: flash flood disaster, prewarning index, concentration model, disaster prevention object, geomorphological parameters

\section{Introduction}

In recent years, the climate change has induced extreme weather conditions across the world, such as the extreme rainfall events. As a result, the flash flood, a rapid flooding in small hilly regions associated with heavy rainfall, became a frequent global disaster with increasing scope of influence (Gruntfest and Handmer, 1999). With complex influencing factors and severe damages, this disaster is difficult to prevent or mitigate, making it the key to flood prevention and mitigation. The critical rainfall is an important parameter in the prewarning and prevention system of flash flood disasters (Li et al., 2014). A pre-warning should be issued when the rainfall is forecasted to reach the critical level, and a warning should be released once the real-time rainfall reaches the critical value. Therefore, the accuracy of critical rainfall is essential to the reduction of casualties and property losses.

Currently, the critical rainfall is mainly determined by the following methods: flash flood guidance (FFG) (WMO, 1994; Villarini et al., 2010; Carpenter et al., 1999; Diagi, 2018; Norbiato et al., 2008; Georgakakos, 2006; Seo et al., 2013; Vizzari et al., 2018; Clark et al., 2014), single-station or regional critical rainfall method based on the characteristic flood-causing rainfall (Chen and Yuan, 2005; Chen et al., 2014), floodcausing flow inversion based on analytical calculation of runoff generation and 
convergence (RGC) (Mao, 2016; Ma, 2017), dynamic critical rainfall method based on different soil saturations (Liu et al., 2010; Ye et al., 2014) and the dynamic critical rainfall method based on various influencing factors (Guo et al., 2016). Below is a brief introduction to each of these methods.

The FFG method fully considers such three factors as rainfall, antecedent soil moisture and the underlying surface (Ren, 2015). Firstly, a control section is selected at the prewarning location, and the characteristic flow of the section is computed according to the river section data of the watershed. Next, the design rainfall and other parameters are inputted to the model, and the rainfall-caused flood is simulated through RGC calculation. Finally, the critical rainfalls in different periods at the target location are determined, considering the impacts of antecedent soil moisture on flash flood. Based on a physical mechanism, the FFG method provides dynamic information for prewarning, thanks to its consideration of rainfall, the underlying surface as well as the impacts of soil water content. Thus, this method has been trusted and adopted by most countries in Europe, the Americas and Africa (Georgakakos, 2006). However, the FFG requires professional support platforms and high-quality data on rainfall. In practice, it is very difficult to acquire the parameters of hydrological model, or set up a complete historical flash flood database to verify the flash flood warning.

As for the single-station or regional critical rainfall method based on the characteristic flood-causing rainfall, it is necessary to collect the data on multiple floodcausing rainfalls. Without considering antecedent moisture and spatiotemporal rainfall distribution, this method faces a high calculation error in regions with fewer floods.

By the flood-causing flow inversion based on analytical calculation of RGC, the critical rainfalls in different prewarning periods under dry, general and wet conditions are computed based on the flood-causing flow and the RGC model of the watershed. The real-time prewarning is realized through two steps: estimating the soil water content and the corresponding critical rainfall in each prewarning period, and comparing the estimated value with the forecasted value. The estimation is bound to bring a large error, if the rainwater condition in the region is managed by a single department. What is worse, this method, taking account of only a few factors, ignores the effects of spatiotemporal distribution of rainfall and preceding rainfall on the bottom water of the river.

Following the dynamic critical rainfall method based on different soil saturations, the soil saturation and rainfall of the watershed in each prewarning period are illustrated as a scatter plot, and a straight line of critical prewarning rainfall is drawn in the scatter plot, dividing the state space of soil saturation and the maximum rainfall in each period into two parts. In this way, the critical rainfall for flash flood prewarning changes with the soil saturation in the watershed, laying the basis for dynamic prewarning. Compared with the previous methods, this strategy fully considers the dynamic variation in soil saturation in actual floods. Nevertheless, the soil saturation-based prewarning method will produce a constant critical rainfall after the soil is saturated with water, which goes against the actual situation.

In the dynamic critical rainfall method based on various influencing factors, the critical rainfall of each event is computed according to the measured rainfall process and the watershed RGC model, and the critical rainfall of each event is correlated with the rainfall characteristics of each event, forming the dynamic critical rainfall curve. This method improves the accuracy of critical rainfall calculation to some extent, as it fully considers how the critical rainfall is affected by the time variation of rainfall, the 
cumulative rainfall, and the antecedent moisture. However, the calculation accuracy needs to be further improved by differentiating the impact degree of various factors on the critical rainfall.

The watershed RGC calculation is fundamental to the computation of the critical rainfall. The calculation of runoff generation, affected by geographic and geomorphic conditions, directly bears on the flooding of the watershed outlet section, which in turn affects the accuracy of critical rainfall and real-time pre-warning. In the existing rainfall calculation methods, the runoff generation is often computed by inference formula method (Liu et al., 2017; Li, 2016) and hydrograph models of multiple units (e.g. empirical unit, instantaneous unit and geomorphological instantaneous unit (Ye et al., 2013; Wang et al., 2018).

Based on five-point generalization, the flood hydrograph obtained by the inference formula method needs manual calibration, as it deviates from the actual situation in the rising and recession phases. Besides, the effects of the underlying surface (e.g. geomorphic conditions) is not taken into account.

The integrated instantaneous unit hydrograph, integrated empirical unit hydrograph, integrated reference formula and geomorphological instantaneous unit hydrograph are all tools to estimate the flood hydrograph in regions lacking the necessary data. Specifically, the integrated unit hydrograph method firstly analyzes the watersheds with measured data in the study area, derives the relationship between the unit hydrograph and the geographic eigenvalues of the watershed, and then deduces the unit hydrograph of the region lacking the necessary data according to the local geographic eigenvalues and the said relationship. Assuming the linearity and time invariance of the set sum, the unit hydrograph is a function of the natural geographic features of the watershed, but cannot be directly adopted for watersheds lacking necessary data.

The geomorphological instantaneous unit hydrograph (GIUH) can acquire the geomorphic features of the watershed in real time, using digital elevation model (DEM), geographic information system (GIS), remote sensing and other means. In addition, these features are digitalized such that the spatiotemporal effects of human activities can be fully considered in hydrological simulation. The overall consideration ensures that the simulated results are close to the actual situation.

In this paper, the geomorphological features of the target watershed are extracted by ArcGIS, and used to establish a runoff generation model based on the geomorphological instantaneous unit hydrograph proposed by Rodriguez-Iturbe and Valdes (R-V GIUH). Then, the established model was adopted to calculate the critical rainfalls of several rainfall events measured in the watershed. Considering such factors as rainfall intensity, cumulative rainfall and antecedent moisture, the author constructed the dynamic critical rainfall model by the radial basis function (RBF), which discloses the dynamic relationship between critical rainfalls of several floods and various influencing factors. The model was trained into the prediction model by the data of several floods, and applied to forecast the dynamic critical rainfall. The research findings shed new light on the calculation of dynamic critical rainfall.

\section{Materials and methods}

\section{Watershed overview}

Located in the center of Xinxian County, Xinyang Prefecture, Central China's Henan Province, the Peihe River mainly flows through a mountainous region with huge 
elevation difference and complex geomorphic features. The watershed (Fig. 1) is covered by yellow brown soil, paddy soil and moisture soil. The climate is relatively humid, with an annual mean rainfall of $1,335 \mathrm{~mm}$. The low vegetation coverage makes the watershed prone to natural disaster and soil erosion. The weather in the watershed could be vastly different from area to area. Thus, heavy rains are commonplace here, leading to severe flash floods. According to statistics, 12 major flash floods has hit the Peihe River watershed since 1949, causing losses of hundreds of million yuan and affecting tens of thousands of people.

In this research, the villages of Xinxian County are selected from the watershed as the objects of disaster prevention. Many of the widely scattered settlements are highly susceptible to flash floods. The villages along the river cann withstand a 20-year flood at the most. Because of the small watershed and short convergence time, the river water will rise above the banks of the rainfall is too intense, causing damages to the villagers.

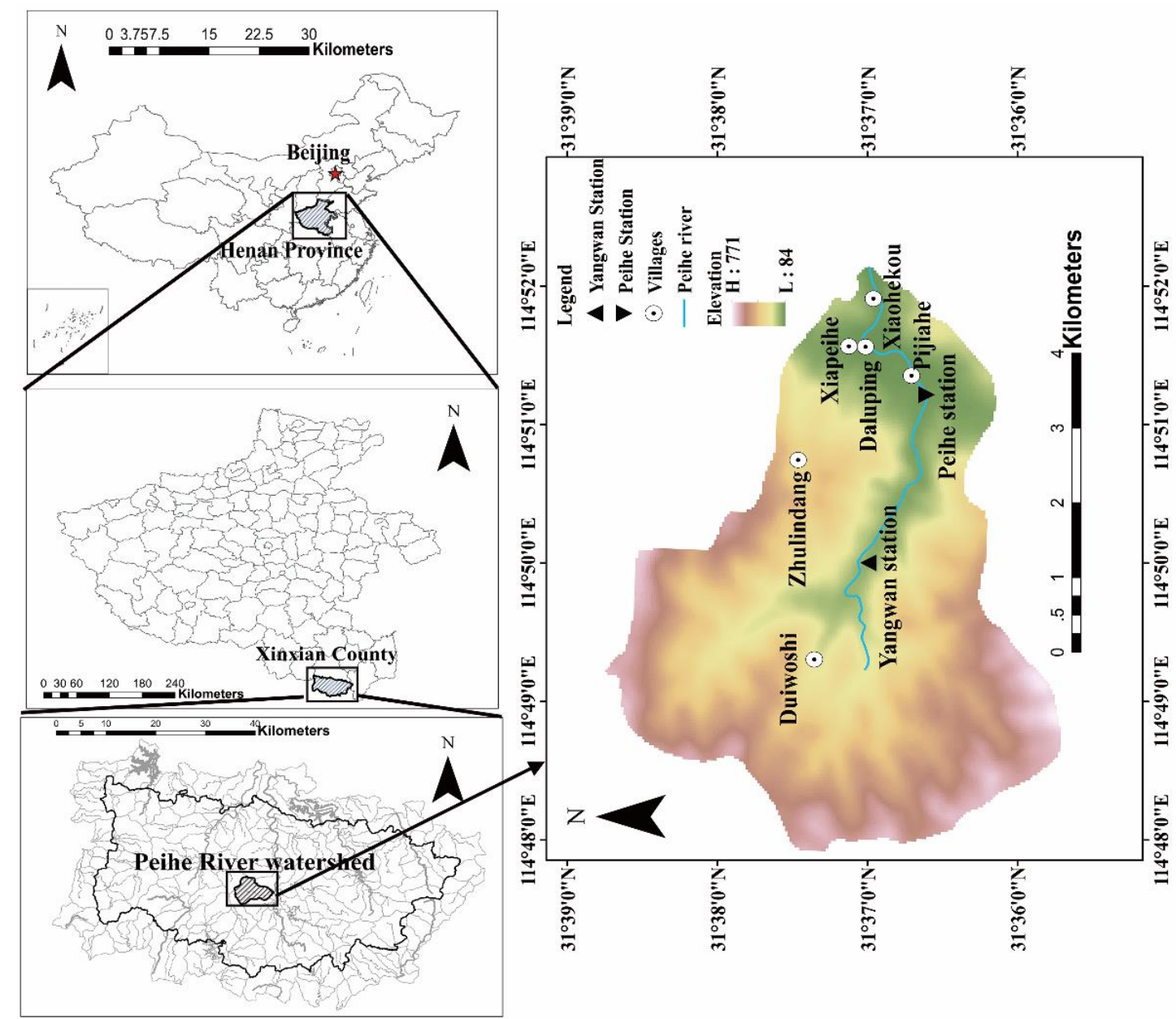

Figure 1. Overview of the Peihe River watershed

There is a rainfall station (Yangwan) and a hydrological station (Peihe) in the Peihe River watershed. The two stations observe such items as precipitation, water level and flow rate. The available data cover the heavy rains in flood season over the 32 years between 1982 and 2013. The data period is sufficiently long to have statistical significance, that is, the data can reveal the actual rainfall features in the watershed. 
Most of the natural river sections are either $\mathrm{V}$-shaped or U-shaped, with a total catchment area of about $21 \mathrm{~km}^{2}$. The prewarning water level of the watershed was determined as $97.3 \mathrm{~m}$ according to the measured large section data of the Peihe River watershed provided by Henan Provincial Flood Prevention Drought Relief Headquarters and the 2015 Flash Flood Disaster Analysis and Evaluation Report of Xinxian County, Henan Province. The flow rate corresponding to the prewarning flow, i.e. the prewarning flow, was determined as $92 \mathrm{~m}^{3} / \mathrm{s}$ by looking up the water level-flow rate relationship curve of the watershed, which was obtained based on the perennial measured flow rates and water levels.

\section{Geomorphologic instantaneous unit hydrograph proposed by Rodriguez-Iturbe and Valdes (R-V GIUH)}

The runoff convergence model of R-V GIUH theory is established based on geomorphic and hydrodynamic parameters of the watershed. The model can reflect the actual geomorphic features with a few easy-to-obtain parameters. In this paper, the general formula proposed by Wen et al. (1991) is adopted to calculate the R-V GIUH of the watershed (Eq. 1):

$$
R-\operatorname{VGIUH}(t)=-\sum_{j=1}^{\Omega}\left\{\lambda_{i}\left[\sum_{i=1}^{j} \theta_{i, \Omega}(0) A_{i j}\right] e^{-\lambda_{j} t}\right\}
$$

where $i$ and $j$ are the orders of rivers $(i \neq j) ; \lambda_{i}$ and $\lambda_{j}$ are the mean waiting time of order $i$ and order $j$ rivers, respectively; $\Omega$ is the order of the river network; $\theta_{i, \Omega}(0)$ is the initial state probability of a order $i$ river in a order $\Omega$ river network, i.e. the size ratio of the watershed of the order $i$ river to the watershed of the entire river network; $A_{i j}$ is the correlation coefficient between the mean waiting time $\lambda_{i}$ and the state transition probability $\mathrm{P}_{i j}\left(\mathrm{P}_{i j}\right.$ is the ratio of the number of order $i$ rivers flowing into order $j$ rivers to the total number of order $i$ rivers; $t$ is time. All these parameters can be calculated based on the geomorphic and hydrodynamic parameters of the watershed.

\section{Extraction and calculation of geomorphic parameters}

The river network of the watershed was extracted from the DEM in the study area using the software Geographic Information System (GIS). Then, the Strahler classification (2015) was performed on the extracted river network, yielding the river section data with watershed orders. On this basis, the geomorphic features of each river section in the watershed were determined, including number, length and catchment area, and the river number ratio $R_{B}$, river length ratio $R_{L}$ and area ratio $R_{A}$ were respectively calculated as follows by the Horton's law (Eqs. 2-4):

$$
\begin{aligned}
& R_{B}=\frac{N_{i-1}}{N_{i}}=C, i=1,2, \cdots, \omega \\
& R_{L}=\frac{\bar{L}_{i}}{\bar{L}_{i-1}}=C, i=1,2, \cdots, \omega
\end{aligned}
$$




$$
R_{A}=\frac{\bar{A}_{i}}{\bar{A}_{i-1}}=C, i=1,2, \cdots, \omega
$$

where $N_{i}$ and $N_{i-1}$ are the number of order $i$ rivers and that of order $i-1$ rivers, respectively; $\bar{L}_{i}$ and $\bar{L}_{i-1}$ are the mean length of order $i$ rivers and that of order $i-1$ rivers, respectively; $\bar{A}_{i}$ and $\bar{A}_{i-1}$ are the mean watershed area that contributes to the runoff of order $i$ rivers and that to the runoff of order $i-1$ rivers, respectively; $C$ is a constant; $\omega$ is the highest order of the river system.

\section{Determination and calculation of hydrodynamic parameters}

The hydrodynamic parameters of a watershed include the Manning's roughness coefficient $n$ and the mean river width $B$. The former was obtained by table look-up according to the local conditions. The latter was generalized as an unknown parameter that varies with the net rainfall intensity $i_{\mathrm{r}}$. The mean waiting time $\lambda_{i}$ of rivers on each order was calculated based on the two parameters. The calculation formulas of $n, B$ and $\lambda_{i}$ are as follows (Eqs. 5-7):

$$
\begin{gathered}
v=0.665 \alpha_{\Omega}^{0.6}\left(i_{r} A_{\Omega}\right)^{0.4} \\
\alpha_{\Omega}=S^{0.5} /\left(n B^{2 / 3}\right) \\
\lambda_{i}=v /\left(\bar{L}_{i} \cdot R_{L}^{i-1}\right)
\end{gathered}
$$

where $i_{r}$ is the net rainfall intensity of each event; $v$ is the flow rate.

\section{Calculation of critical rainfall of each event}

The critical rainfall of each event refers to the critical rainfall in the prewarning period of a flood-causing rainfall event. It is the basis for determining the dynamic critical rainfall for the disaster prevention in the target location. In light of the measured rainfall data, the value of this parameter was obtained by the RGC calculation through the following steps.

(1) The rainfall process from the beginning of rainfall to any time $\mathrm{T}$ was intercepted from the rainfall data, the RGC process of the watershed was calculated using the rainfall-runoff correlation map and the R-V GIUH, and the flood hydrograph was derived for the rainfall event.

(2) The peak flow Qpeak in this rainfall event was obtained based on the flood hydrograph. If the peak flow is greater than the prewarning flow Qprewarning, then the flash flood has occurred. In this case, the rainfall process from the beginning of rainfall to any time T was intercepted again, and Step (1) was repeated until the peak flow is smaller than the prewarning flow.

(3) When the peak flow is smaller than the prewarning flow, the rainfall in the $T+1$ period was given a value in ascending order, and the flood process induced by the rainfall in this period was derived. If the peak flow is close to the prewarning flow, then the rainfall in the $T+1$ period is the critical rainfall of the event after the rainfall event lasts for a period of $\mathrm{T}$. 
(4) The critical rainfalls of different events can be determined by the same method.

\section{RBF-based prediction of dynamic critical rainfall}

The RBF neural network (RBFNN) is a RBF-based artificial neural network. With a three-layer feedforward structure, the network has a nonlinear mapping from the input layer to the output layer and a linear mapping from the hidden layer to the output layer. The good nonlinearity enables the RBFNN to approximate any nonlinear function, disclose the intractable regularity in the system, and describes the potential relationship between the predictive index and the influencing factors. Known for its good generalization ability, the network has been successfully applied to nonlinear function approximation, time series analysis, data classification, pattern recognition, system modeling and fault diagnosis. Considering the complex nonlinear relationship between critical rainfall and its influencing factors, the RBFNN is a desirable tool to build the dynamic relationship model about the critical rainfall and the influencing factors. This network can be implemented despite the lack of data in regions suffering from flash floods, as it requires only a few training samples and outputs a unique training outcome.

In this paper, antecedent moisture, cumulative rainfall and rainfall intensity are taken as an input, and the critical rainfall of each event was considered as the output to construct a three-layer neural network. Through the training of the learning samples and the checking of the test samples, the dynamic relationships between the critical rainfall and the influencing factors were established, forming the dynamic critical rainfall prediction model (Fig. 2). Mathematical theory of RBFNN is detailed in Zeng et al. (2018).

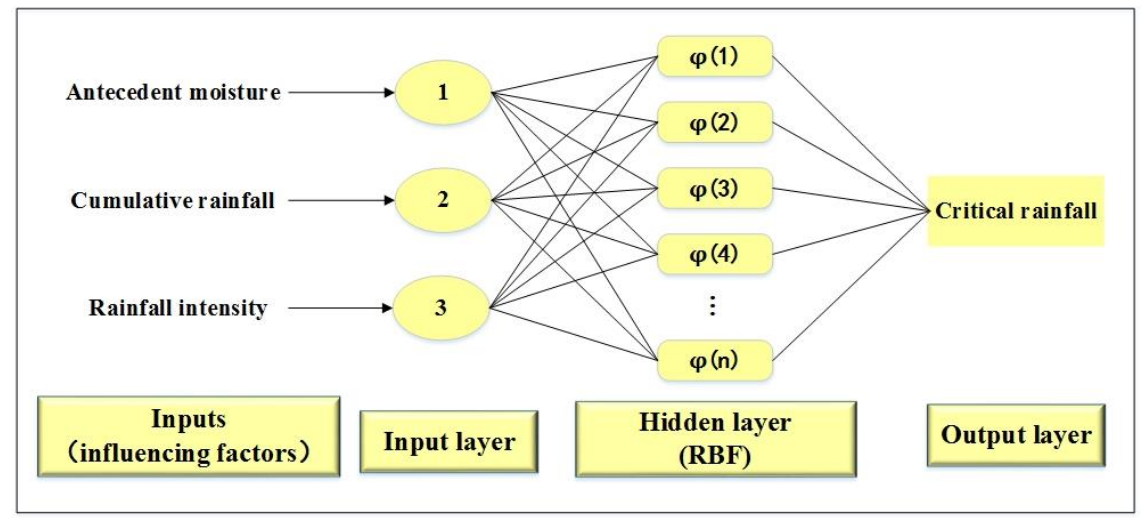

Figure 2. structure of the dynamic critical rainfall prediction model

\section{Results}

\section{Runoff generation plan}

The runoff generation was calculated based on the rainfall-runoff correlation map (Fig. 3), which was checked and modified against the 14 typical floods in the Peihe River watershed between 1982 and 2013.

As shown in Figure 3, since the 1980s, the actual rainfall-runoff curve in the Peihe River watershed was basically consistent with that in the map, so was the runoff volume. This means the rain and flood data are valid, and the rainfall-runoff correlation map can be adopted for runoff generation calculation. 


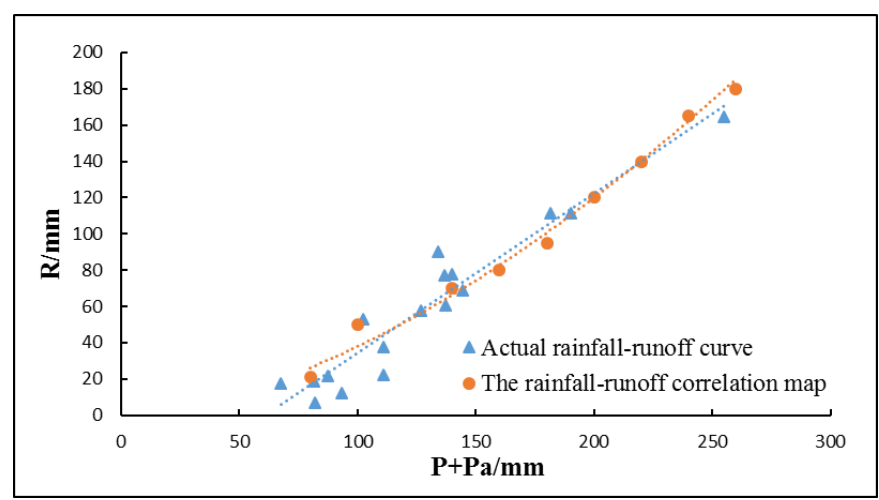

Figure 3. Rainfall-runoff correlation map of the Peihe River watershed

\section{Runoff convergence plan}

Parameter extraction and model construction

The digital elevation data were downloaded from the Geospatial Data Cloud (http://www.gscloud.cn), with a spatial resolution of $30 \mathrm{~m}$. The data about the Peihe River watershed were processed on ArcMap, producing the river network in the watershed. The network was then divided into four orders by the Strahler classification (Fig. 4). The number and total length of rivers in each order were counted (Table 1). Next, the watershed was split into several sub-watersheds (Fig. 5). The area of each sub-watershed was determined, and the relevant geomorphic parameters were computed by Equations 2-4 (Table 1).

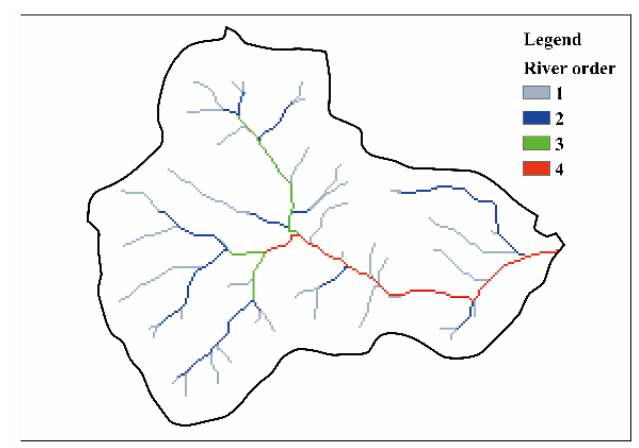

Figure 4. River network classification

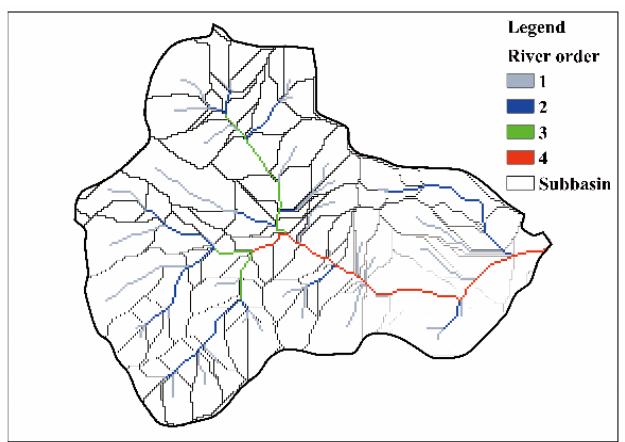

Figure 5. Vector graph of catchment area 
Table 1. Geomorphic parameters of the Peihe River watershed

\begin{tabular}{c|c|c|c|c|c|c|c|c}
\hline $\begin{array}{c}\text { River } \\
\text { order }\end{array}$ & $\begin{array}{c}\text { River } \\
\text { numbers }\end{array}$ & $\begin{array}{c}\text { Total length } \\
\text { of the river } \\
(\mathbf{k m})\end{array}$ & $\begin{array}{c}\text { Average } \\
\text { length of the } \\
\text { river }(\mathbf{k m})\end{array}$ & $\begin{array}{c}\text { Total area of the } \\
\text { catchment }\left(\mathbf{k m}^{\mathbf{2}}\right)\end{array}$ & $\begin{array}{c}\text { Average area of } \\
\text { the catchment } \\
\mathbf{k m}^{\mathbf{2}} \mathbf{)}\end{array}$ & $\begin{array}{c}\text { River } \\
\text { number } \\
\text { ratio }\end{array}$ & $\begin{array}{c}\text { River } \\
\text { length } \\
\text { ratio }\end{array}$ & $\begin{array}{c}\text { Area } \\
\text { ratio }\end{array}$ \\
\hline 1 & 47 & 20.52 & 0.43 & 12.20 & 0.25 & & & \\
2 & 12 & 10.20 & 0.85 & 4.14 & 0.34 & & & \\
3 & 3 & 3.45 & 1.15 & 1.85 & 0.61 & & 2.63 & 2.58 \\
4 & 1 & 5.10 & 5.10 & 2.86 & 2.86 & & & \\
\hline
\end{tabular}

The watershed area was acquired as $21.07 \mathrm{~km}^{2}$ during the extraction of the river network. The area threshold was $0.1 \mathrm{~km}^{2}$, and the corresponding stream gradient was $13.51 \%$. The Manning's roughness coefficient was determined as $0.025 \mathrm{~m}$ by table lookup. The mean river width $B$ was initially determined as $2 \mathrm{~m}$ according to the section data extracted on the GIS. On this basis, the value of $B$ was calibrated through the simulation of 4 measured floods. The data of the 4 floods were fitted to obtain the relationship between $B$ and the net rainfall intensity $i_{r}: B=0.326 \ln \left(i_{r}\right)+1.9312$. With these parameters, the R-V GIUH of each flood was derived by (Eq. 1).

\section{Model verification}

To verify the applicability of R-V GIUH in regions lacking hydrological data, the RV GIUH was created based on the parameters of 8 rainfall events measured by Peihe Hydrological Station from 1982 to 2013, and the resulting unit hydrographs were compared with the measured data. Figure 6 and Table 2 show the comparison between the simulated results and the measured results of the 8 floods.

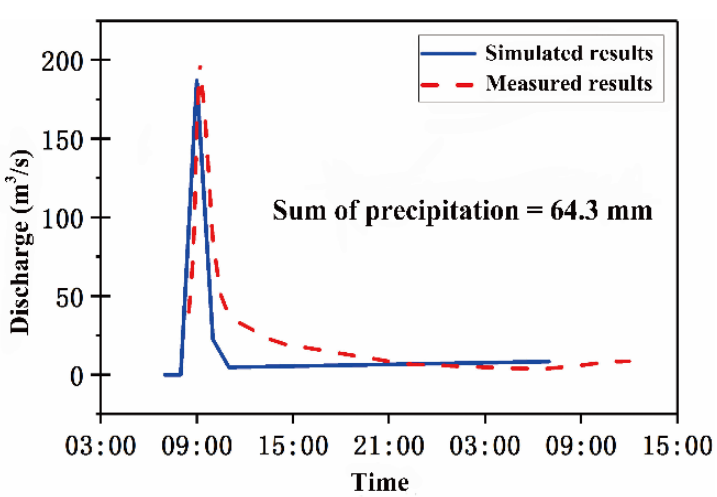

(a) July 19, 1982

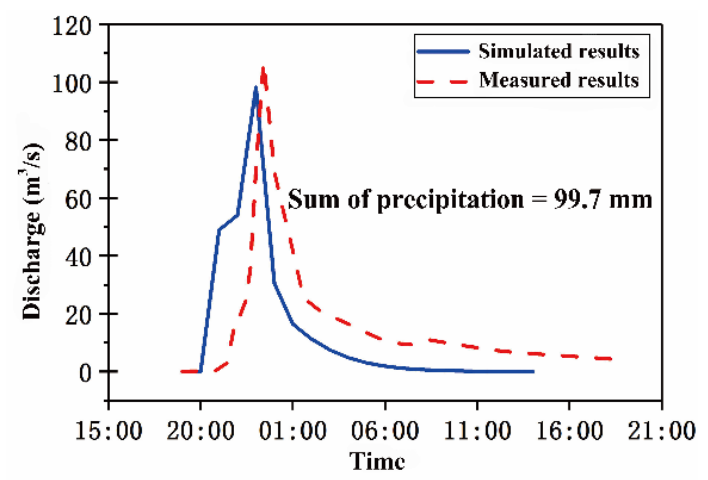

(c) August 8, 1984

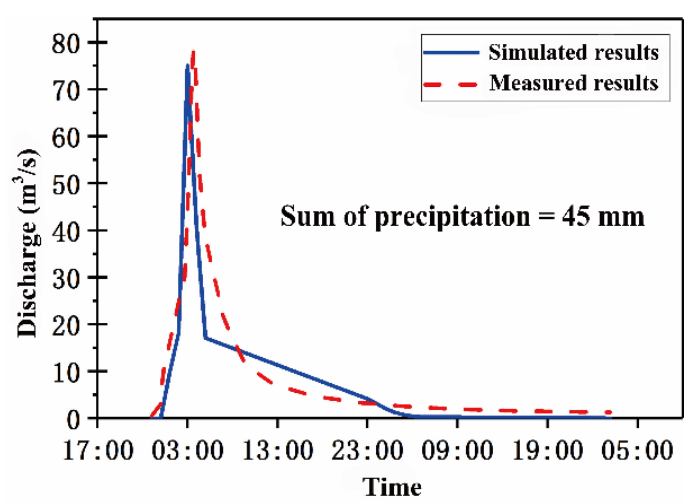

(b) July 17, 1983

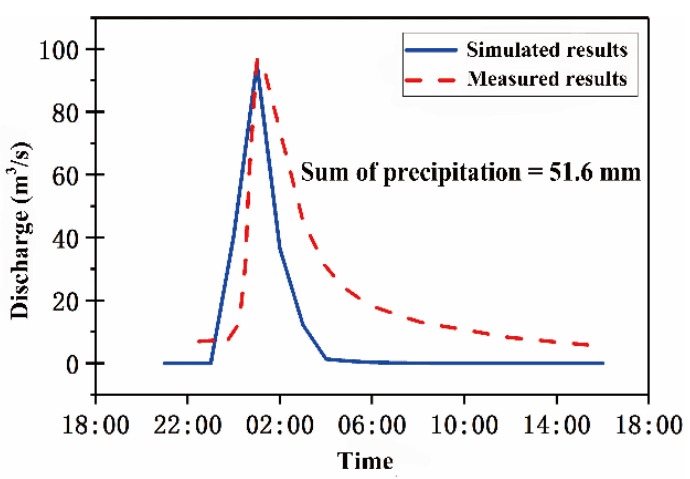

(d) July 17, 1986 


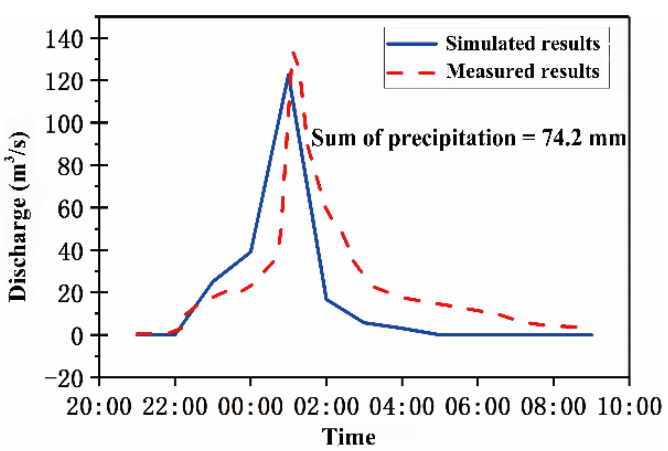

(e) July 5, 1987

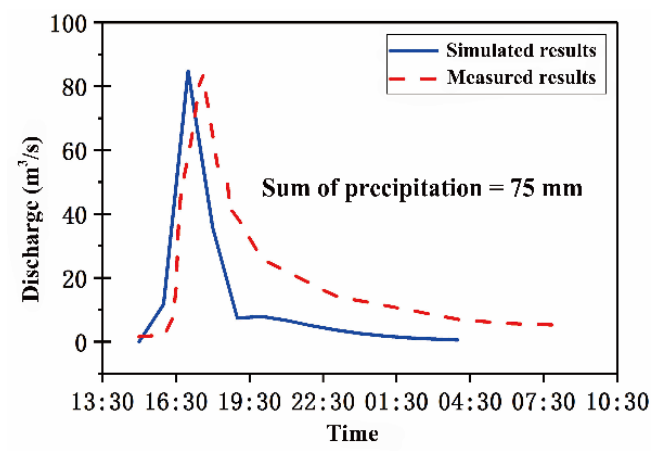

(g) July 1, 2007

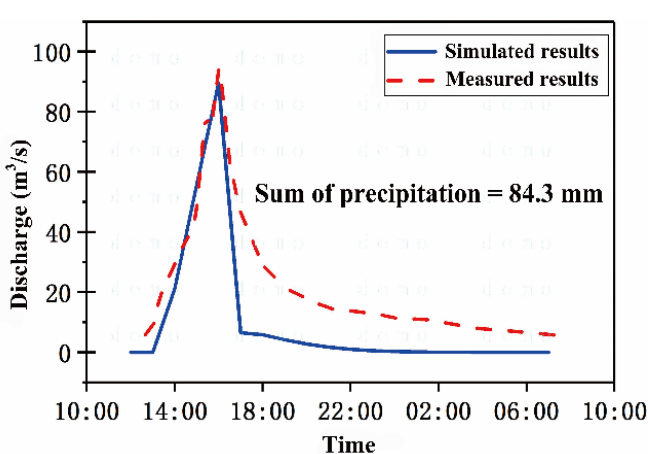

(f) July 19, 1990

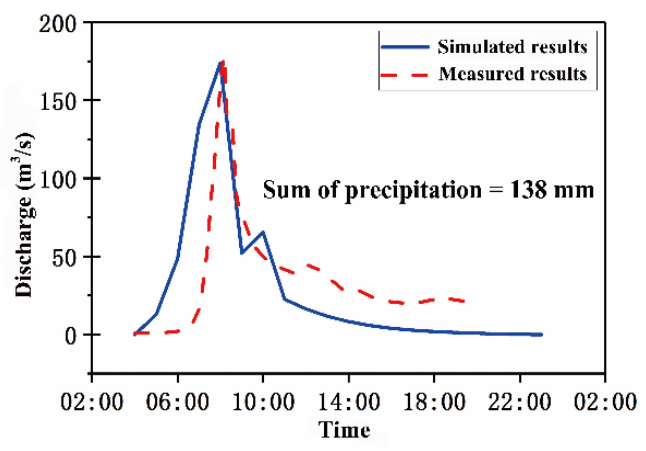

(h) August 16, 2008

Figure 6. Comparison between the simulated results and the measured results of the 8 floods

Table 2. Comparison between the simulated results and the measured results of the 8 floods

\begin{tabular}{|c|c|c|c|c|}
\hline Flood number & $\begin{array}{c}\text { Measured } \\
\text { peak } /\left(\mathrm{m}^{3} / \mathbf{s}\right)\end{array}$ & $\begin{array}{c}\text { Simulated } \\
\text { peak } /\left(\mathbf{m}^{3} / \mathbf{s}\right)\end{array}$ & $\begin{array}{c}\text { Relative } \\
\text { error } /\left(\mathbf{m}^{3} / \mathbf{s}\right)\end{array}$ & $\begin{array}{c}\text { The time error of } \\
\text { peak } /(\min )\end{array}$ \\
\hline July 19, 1982 & 200 & 187 & -13 & 18 \\
\hline July 17,1983 & 78 & 75.09 & -2.91 & 40 \\
\hline August 8, 1984 & 107 & 98.29 & -8.71 & 25 \\
\hline July 17, 1986 & 96.6 & 95.43 & -1.17 & 0 \\
\hline July 5, 1987 & 133 & 122.64 & -10.36 & 10 \\
\hline July 19, 1990 & 94.1 & 89.6 & -4.5 & 0 \\
\hline July 1, 2007 & 83.5 & 84.8 & 1.3 & 36 \\
\hline August 16, 2008 & 178 & 174.19 & -5.81 & 9 \\
\hline
\end{tabular}

Figure 6 and Table 2 show that the simulated flood process was basically the same with the measured situation. In the recession phase, the simulated results were slightly faster than the measured results. The minor deviation does not affect the computing accuracy of critical rainfalls, because critical rainfall mainly depends on the peak flow and the situation of the rising phase. Compared with the measured results, the simulated floods rose fast and reached the peak flow early at a low volume. As a result, the simulated critical rainfalls were slightly below the measured values. For safety reasons, the slightly lower critical rainfalls are safer. Overall, the geomorphic-based R-V GIUH model enjoys a high accuracy in runoff generation calculation, and the simulated results are suitable for the simulation of the flood process and the computation of the critical rainfalls. 


\section{Analysis of calculated critical rainfall of each event}

Two typical prewarning periods, namely $1 \mathrm{~h}$ and $3 \mathrm{~h}$, were selected according to the rainstorm features, watershed area and underlying surface of the target region. The critical rainfall of 16 measured floods in the Peihe River between 1982 and 2013 were calculated (Table 3). To verify the accuracy of the critical rainfall calculation by $\mathrm{R}-\mathrm{V}$ GIUH, the critical rainfalls were compared with the actual rainfalls in the prewarning periods to see if flash flood prewarning is necessary, and the prewarning was verified based on whether the actual flow reached the prewarning flow.

Table 3. Calculated and measured results on critical rainfall of each event

\begin{tabular}{|c|c|c|c|c|c|c|}
\hline $\begin{array}{c}\text { Prewarning } \\
\text { periods }\end{array}$ & Time & $\begin{array}{c}\text { Measured } \\
\text { discharge }\left(\mathbf{m}^{3} / \mathbf{s}\right)\end{array}$ & $\begin{array}{c}\text { Total rainfall of } \\
\text { periods }(\mathbf{m m})\end{array}$ & $\begin{array}{c}\text { Critical } \\
\text { rainfall }(\mathbf{m m})\end{array}$ & \begin{tabular}{|c|} 
Prewarned \\
or not
\end{tabular} & $\begin{array}{c}\text { Correct } \\
\text { or not }\end{array}$ \\
\hline \multirow{16}{*}{$1 \mathrm{~h}$} & $1982 / 07 / 19 / 09$ & 186 & 54.4 & 38.25 & $\mathrm{Y}$ & $\sqrt{ }$ \\
\hline & $1983 / 09 / 16 / 03$ & 73.1 & 25.8 & 48.64 & $\mathrm{~N}$ & $\sqrt{ }$ \\
\hline & $1984 / 08 / 08 / 23$ & 90.31 & 36 & 76.16 & $\mathrm{~N}$ & $\sqrt{ }$ \\
\hline & $1985 / 07 / 13 / 08$ & 46.4 & 25.9 & 33.29 & $\mathrm{~N}$ & $\sqrt{ }$ \\
\hline & $1986 / 07 / 18 / 01$ & 93.86 & 31.2 & 29 & Y & $\sqrt{ }$ \\
\hline & 1987/07/06/01 & 121.59 & 36.6 & 26.72 & Y & $\sqrt{ }$ \\
\hline & 1988/09/09/01 & 55 & 10.6 & 69.41 & $\mathrm{~N}$ & $\sqrt{ }$ \\
\hline & $1990 / 07 / 19 / 16$ & 78.6 & 29.9 & 78.82 & $\mathrm{~N}$ & $\sqrt{ }$ \\
\hline & $1991 / 07 / 03 / 13$ & 60.7 & 17.5 & 23.26 & $\mathrm{~N}$ & $\sqrt{ }$ \\
\hline & $1993 / 06 / 21 / 13$ & 37.1 & 23 & 21.38 & $\mathrm{Y}$ & $x$ \\
\hline & $1995 / 04 / 22 / 05$ & 32.1 & 22.4 & 81.61 & $\mathrm{~N}$ & $\sqrt{ }$ \\
\hline & $1996 / 07 / 14 / 17$ & 104 & 23.2 & 16.70 & $\mathrm{Y}$ & $\sqrt{ }$ \\
\hline & $1998 / 07 / 02 / 20$ & 48.1 & 32.8 & 29.93 & Y & $x$ \\
\hline & $1999 / 06 / 27 / 14$ & 34.4 & 10.4 & 56.4 & $\mathrm{~N}$ & $\sqrt{ }$ \\
\hline & $2000 / 06 / 29 / 01$ & 59.8 & 26 & 84.01 & $\mathrm{~N}$ & $\sqrt{ }$ \\
\hline & $2002 / 06 / 19 / 19$ & 101.0 & 34 & 33.23 & $\mathrm{Y}$ & $\sqrt{ }$ \\
\hline \multirow{16}{*}{$3 \mathrm{~h}$} & $1982 / 07 / 19 / 09$ & 186 & 58.9 & 41.66 & $\mathrm{Y}$ & $\sqrt{ }$ \\
\hline & 1983/09/16/03 & 78.2 & 37.8 & 61.1 & $\mathrm{~N}$ & $\sqrt{ }$ \\
\hline & $1984 / 08 / 08 / 23$ & 90.31 & 75 & 94.7 & $\mathrm{~N}$ & $\sqrt{ }$ \\
\hline & $1985 / 07 / 13 / 10$ & 51.8 & 42.9 & 39.5 & $\mathrm{Y}$ & $x$ \\
\hline & 1986/07/18/01 & 93.86 & 38.8 & 33.9 & $\mathrm{Y}$ & $\sqrt{ }$ \\
\hline & 1987/07/06/01 & 133 & 45.2 & 41.6 & Y & $\sqrt{ }$ \\
\hline & 1988/09/09/01 & 66.2 & 22.3 & 96.4 & $\mathrm{~N}$ & $\sqrt{ }$ \\
\hline & $1990 / 07 / 19 / 16$ & 78.6 & 59.2 & 91.34 & $\mathrm{~N}$ & $\sqrt{ }$ \\
\hline & $1991 / 07 / 03 / 13$ & 60.7 & 43.6 & 77.2 & $\mathrm{~N}$ & $\sqrt{ }$ \\
\hline & $1993 / 06 / 21 / 13$ & 37.1 & 45 & 39.7 & $\mathrm{Y}$ & $x$ \\
\hline & $1995 / 04 / 22 / 06$ & 45.6 & 41.6 & 101.3 & $\mathrm{~N}$ & $\sqrt{ }$ \\
\hline & $1996 / 07 / 14 / 17$ & 104 & 55.5 & 43.68 & $\mathrm{Y}$ & $\sqrt{ }$ \\
\hline & $1998 / 07 / 02 / 20$ & 48.1 & 42.3 & 44.34 & $\mathrm{~N}$ & $\sqrt{ }$ \\
\hline & $1999 / 06 / 27 / 14$ & 34.4 & 25.1 & 61.7 & $\mathrm{Y}$ & $\sqrt{ }$ \\
\hline & $2000 / 06 / 29 / 02$ & 63 & 38 & 98.4 & $\mathrm{~N}$ & $\sqrt{ }$ \\
\hline & $2002 / 06 / 19 / 20$ & 147.00 & 66 & 57.63 & $\mathrm{~N}$ & $\sqrt{ }$ \\
\hline
\end{tabular}

$\mathrm{Y}$ : there is prewarning; $\mathrm{N}$ : there is no prewarning; $\sqrt{ }$ : the prewarning is correct; $\times$ : the prewarning is incorrect 
Table 3 shows that two prewarning based on the $1 \mathrm{~h}$ and $3 \mathrm{~h}$ critical rainfalls were incorrect, putting the pass rate at $87.5 \%$. The failed cases were analyzed, revealing that the critical rainfalls deviated slightly from the actual rainfalls. The deviation falls within the error tolerance. Overall, the R-V GIUH outputted accurate critical rainfalls.

\section{Dynamic critical rainfall models and accuracy test}

According to the disaster-causing mechanism of flash flood, the occurrence of flash flood in a region not only depends on the preceding rainfall, cumulative rainfall and rainfall intensity, but also on rainfall distribution and the bottom water of the river. The latter two factors are already reflected by the cumulative rainfall and the critical rainfall of each event, respectively. Hence, our dynamic critical rainfall model only considers the preceding rainfall (antecedent moisture), cumulative rainfall (the total rainfall from the start to a moment before the prewarning) and rainfall intensity (the rainfall of a period before the prewarning).

In light of the critical rainfall calculation of the said 16 floods, the preceding rainfall, cumulative rainfall and rainfall intensity were taken as the inputs, and the critical rainfall as the output. The first 12 floods were used as calibration samples and the last 4 as test samples. Then, the prediction model was created in different scales through RBFNN training to predict the dynamic critical rainfall. The simulated results are contrasted with the actual results in Figure 7.
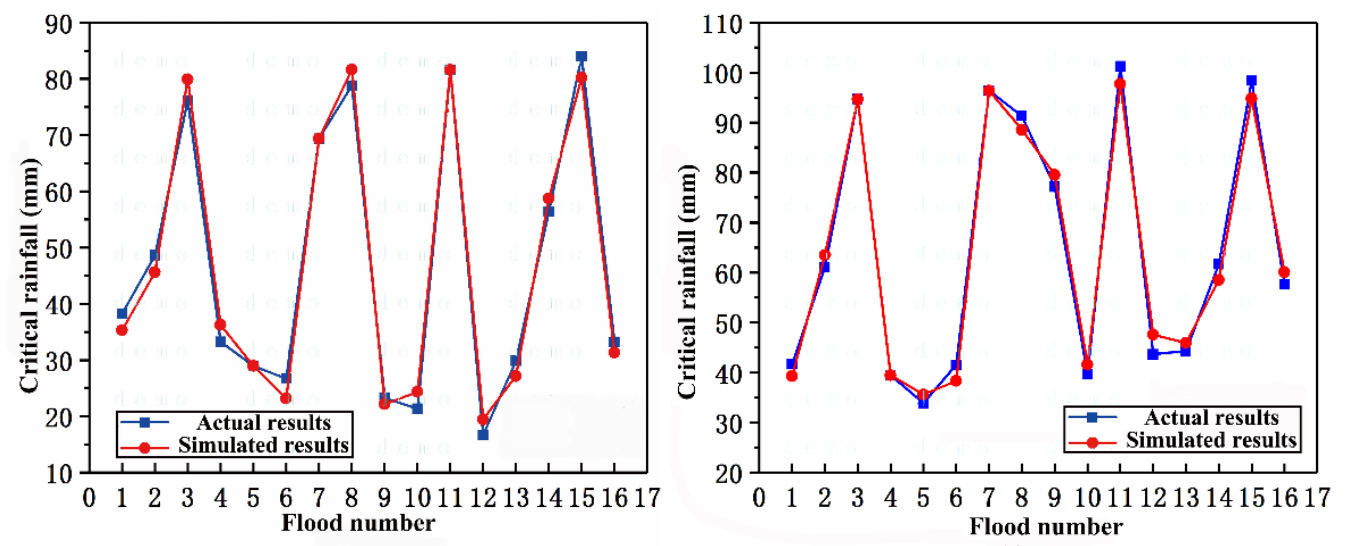

Figure 7. Simulated results of dynamic critical rainfall prediction

Figure 7 shows little difference between the simulated and calculated values, indicating that our model is suitable for the prediction of dynamic critical rainfall. To further verify its applicability, the model was adopted to predict the dynamic critical rainfalls of another 6 floods, and the results were also tested by the actual prewarning results (Table 4). The flood-causing flow inversion based on analytical calculation of RGC was introduced to determine the static critical rainfalls that only considers the preceding rainfall and to issue prewarning for the $1 \mathrm{~h}$ and $3 \mathrm{~h}$ periods, aiming to confirm the completeness of our indices and the superiority of our model. The calculated results are listed in Table 4.

It can be seen from Table 4 that all dynamic critical rainfall prewarning for the $1 \mathrm{~h}$ period were successful, while five out of the six prewarning for the $3 \mathrm{~h}$ period were successful, putting the pass rate at $83.3 \%$. By contrast, the pass rates of static critical 
rainfall prewarning were $66.6 \%$ and $50 \%$, respectively. In fact, the RBF-based dynamic prediction was more accurate than the contrastive calculation method. To sum up, the R-V GIUH-based critical rainfall prewarning is of high accuracy, and the RBFNNbased dynamic prediction model thus established does well in the forecast of the critical rainfall.

Table 4. Verification of the results predicted by our dynamic critical rainfall model

\begin{tabular}{|c|c|c|c|c|c|c|c|c|c|}
\hline \multirow{2}{*}{ 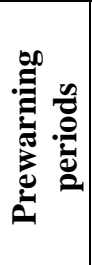 } & \multirow[b]{2}{*}{ Time } & \multirow{2}{*}{ 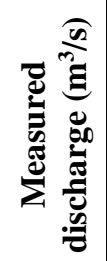 } & \multirow{2}{*}{ 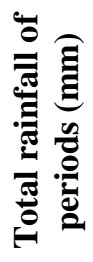 } & \multicolumn{3}{|c|}{$\begin{array}{c}\text { Dynamic critical rainfall } \\
\text { prewarning }\end{array}$} & \multicolumn{3}{|c|}{$\begin{array}{c}\text { Static critical rainfall } \\
\text { prewarning }\end{array}$} \\
\hline & & & & $\mathrm{P}_{\mathrm{d}} / \mathrm{mm}$ & $\begin{array}{c}\text { Prewarned } \\
\text { or not }\end{array}$ & $\begin{array}{l}\text { Correct } \\
\text { or not }\end{array}$ & $\mathrm{P}_{\mathrm{s}} / \mathrm{mm}$ & $\begin{array}{c}\text { Prewarned } \\
\text { or not }\end{array}$ & $\begin{array}{l}\text { Correct } \\
\text { or not }\end{array}$ \\
\hline \multirow{6}{*}{$1 \mathrm{~h}$} & $2003 / 07 / 08 / 18$ & 137.0 & 28.7 & 25.3 & $\bar{Y}$ & $\sqrt{ }$ & 45.8 & $\mathrm{~N}$ & $x$ \\
\hline & 2004/07/18/06 & 69.6 & 19.1 & 43.4 & $\mathrm{~N}$ & $\sqrt{ }$ & 67.0 & $\mathrm{Y}$ & $x$ \\
\hline & $2005 / 09 / 02 / 15$ & 32.7 & 15 & 24.5 & $\mathrm{~N}$ & $\sqrt{ }$ & 47.5 & $\mathrm{~N}$ & $\sqrt{ }$ \\
\hline & $2007 / 07 / 01 / 17$ & 66.2 & 17.1 & 62.3 & $\mathrm{~N}$ & $\sqrt{ }$ & 52.0 & $\mathrm{~N}$ & $\sqrt{ }$ \\
\hline & $2008 / 08 / 16 / 08$ & 161 & 38.6 & 33.2 & $\mathrm{Y}$ & $\sqrt{ }$ & 32.1 & $\mathrm{Y}$ & $\sqrt{ }$ \\
\hline & $2010 / 07 / 16 / 21$ & 43.2 & 20 & 51.1 & $\mathrm{~N}$ & $\sqrt{ }$ & 32.1 & $\mathrm{~N}$ & $\sqrt{ }$ \\
\hline \multirow{6}{*}{$3 \mathrm{~h}$} & $2003 / 07 / 08 / 19$ & 163.00 & 33 & 33.4 & $\mathrm{~N}$ & $x$ & 63.0 & $\mathrm{~N}$ & $x$ \\
\hline & $2004 / 07 / 18 / 06$ & 69.6 & 47 & 76.7 & $\mathrm{~N}$ & $\sqrt{ }$ & 83.4 & $\mathrm{Y}$ & $x$ \\
\hline & $2005 / 09 / 02 / 16$ & 46.3 & 19 & 27.2 & $\mathrm{~N}$ & $\sqrt{ }$ & 68.3 & $\mathrm{~N}$ & $\sqrt{ }$ \\
\hline & $2007 / 07 / 01 / 18$ & 66.2 & 32.3 & 89.5 & $\mathrm{~N}$ & $\sqrt{ }$ & 75.4 & $\mathrm{~N}$ & $\sqrt{ }$ \\
\hline & $2008 / 08 / 16 / 09$ & 178 & 53 & 41.7 & $\mathrm{Y}$ & $\sqrt{ }$ & 56.7 & $\mathrm{~N}$ & $x$ \\
\hline & $2010 / 07 / 16 / 21$ & 43.2 & 26 & 60.4 & $\mathrm{~N}$ & $\sqrt{ }$ & 56.7 & $\mathrm{~N}$ & $\sqrt{ }$ \\
\hline
\end{tabular}

$\mathrm{P}_{\mathrm{d}}$ : the critical rainfall is dynamic; $\mathrm{P}_{\mathrm{s}}$ : the critical rainfall is static; $\mathrm{Y}$ : there is prewarning; $\mathrm{N}$ : there is no prewarning; $\sqrt{ }$ : the prewarning is correct; $\times$ : the prewarning is incorrect

\section{Discussion}

The critical rainfall is an important tool for the prewarning of flash floods. It is very meaningful to probe into this index. In this paper, the critical rainfall is investigated based on the GIUH and the RBFNN, yielding fruitful results. However, there are some shortcomings with our research. Next, the research findings are compared with the relevant studies in two aspects.

Our research discovers that, while the GIUH-based simulation output close-to-reality flood process, the simulated peak flow appears earlier and smaller than the measured data, causing the underestimation of the critical rainfall. This conclusion agrees well with the research of Tang (2017) and Wang et al. (2018). Meanwhile, the test results in Table 3 show a good overall accuracy, but the underestimated critical rainfall may lead to wrong prewarning of several floods that do not cause disasters. New solution should be looked for to solve this problem.

Currently, the flash floods can also be simulated by distributed hydrological models, such as the geomorphology-based hydrological model (GBHM) (Liu et al., 2010), the Xin'anjiang (XAJ) model (Ye et al., 2014), the Hydrologic Engineering Center's Hydrological Modeling System (HEC-HMS) model (Liu, 2016; Guan et al., 2017), and the grid XAJ model (Liu et al., 2017). These models can simulate the flood process 
more realistically and accurately than the GIUH-based model, and can also be adopted to compute the critical rainfall. Nonetheless, most distributed hydrological models have lots of parameters, which need to be determined by a long series of data. In this respect, the GIUH-based method enjoys certain advantages with relatively few and easy-toobtain parameters. In future research and applications, the flood computing method should be selected according to the local data.

In addition, the prewarning results of rainfall events differed with time scales, as acquired through the calculation of critical rainfall of each event. For example, the 1998070220 rainfall event was prewarned incorrectly on the $1 \mathrm{~h}$ scale and correctly on the $3 \mathrm{~h}$ scale, while the 1985071310 rainfall event was prewarned incorrectly on the $3 \mathrm{~h}$ scale and correctly on the $1 \mathrm{~h}$ scale. The results are consistent with the findings of Guo et al. (2016). Analysis shows that the prewarning effect of short, heavy rainfall is negatively correlated with the time scale. In actual application, the critical rainfalls on different time scales should be considered fully in the prewarning process, such as to reduce false warning and increase prewarning accuracy.

Besides flood computation, the dynamic relationship between the critical rainfall and the influencing factors also bears on the prewarning of flash floods. Many scholars (Liu et al., 2010; Ye et al., 2014; Guan et al., 2017; Guo et al., 2016) have explored this relationship via linear regression and correlation analysis. These methods can output accurate dynamic critical rainfall. However, none of them differentiate between influencing factors on their impact over the critical rainfall. In fact, the influencing factors are simply superimposed in the relevant studies. To further improve the computing accuracy of critical rainfall, this paper sets up the dynamic relationships between critical rainfall and multiple influencing factors based on the RBFNN. The model was proved accurate in prewarning through the analysis on its calibration, test and prediction results. However, the RBFNN, as a black box model, cannot clearly quantify the degree of impact of each influencing factor on the critical rainfall. The prediction results only confirm that the critical rainfall is affected in different degrees by various factors, namely, preceding rainfall, rainfall process and the bottom water of the river, and the relationships between critical rainfall and these factors are complex. To enhance the accuracy of flash flood prewarning and rationalize decision-making for disaster prevention and mitigation, it is necessary to further explore how these factors affect the dynamic variation in critical rainfall.

\section{Conclusions}

The geomorphic-based R-V GIUH runoff convergence model has a few easy-toobtain parameters and requires no detailed hydrological or geomorphic data. It is suitable for computing the runoff convergence of flash flood in regions lacking data on the disaster. Besides, the model can output good results on runoff convergence. In particular, the simulated flow and time of flood peaks in the rising phase, which is important to the determination of critical rainfall, are close to the measured results. As a result, the model can predict the critical rainfall very accurately.

The critical rainfall is jointly determined by such factors as preceding rainfall, cumulative rainfall and rainfall intensity. The RBFNN-based dynamic critical rainfall prediction model is a desirable tool to describe the complex relationship between the critical rainfall and its influencing factors, laying a good basis for accurate prewarning. 


\section{REFERENCES}

[1] Carpenter, T. M., Sperfslage, J. A., Georgakakos, K. P., Sweeney, T., Fread, D. L. (1999): National threshold runoff estimation utilizing GIS in support of operational flash flood warning systems. - Journal of Hydrology 224: 21-44.

[2] Chen, G. Y., Yuan, Y. M. (2005): Research on analysis and computation method of critical precipitation amount of torrential flood. - Yangtze River 36(12): 40-43.

[3] Chen, Z. L., Huang, G. R., Cheng, G. D. (2014): Research on the calculation methods for critical rainfall of mountain torrent disasters of small watershed. - China Rural Water and Hydropower 6: 82-85.

[4] Clark, R. A, Gourley, J. J, Flamig, Z. L, Hong, Y., Clark, E. (2014): CONUS-wide evaluation of National Weather Service flash flood guidance products. - Weather and Forecasting. https://doi.org/10.1175/WAF-D-12-00124.1.

[5] Diagi, B. E. (2018): Analysis of rainfall trend and variability in Ebonyi state, South Eastern Nigeria. - Environmental and Earth Sciences Research Journal 5(3): 53-57.

[6] Georgakakos, K. P. (2006): Analytical results for operational flash flood guidance. Journal of Hydrology 317(s1-2): 81-103.

[7] Gruntfest, E., Handmer, J. (1999): Coping with Flash Flood. - Kluwer Academic Publishers, The Netherlands.

[8] Guan, X. X., Yao, X. Y., Shen, J., Song. Y. R., Chu, H. C. (2017): Study on multidimensional dynamic critical rainfall flash flood warning based on distributed model. - Jiangsu Water Resources 12: 42-46.

[9] Guo, K. L., Liang, G. H., He, B. (2016): Dynamic critical precipitation flash flood warning method and its application based on API hydrologic model. - Water Resources and Power 34(12): 74-77.

[10] Li, H. X., Qing, G. H., Wang, X., Miao, R., Liu, Y. F. (2014): Advances in Study on Flash Flood Forecast and Warning. - Journal of China Hydrology 34(5): 14-16.

[11] Li, K. X. (2016); Calculation method of flash flood warning rainfall based on reasoning formula. - Journal of China Hydrology 1: 84-87.

[12] Liu, C. Y., Wu, J. H., Gao, J., Yang, D. M., Liu, Y. M. (2017): Research on calculation method of critical rainfall of flash flood disaster in data deficient region. - China Rural Water and Hydropower 5: 166-169.

[13] Liu, S. Y., Jiang, S. H., Ren, L. L. (2017): Calculation of critical rainfall for earlywarning of mountain flood based on distributed hydrological model. - Journal of Hohai University (Natural Sciences) 45(5): 384-390.

[14] Liu, Y. (2016): Research on the Early-Warning System of Mountain Torrent Disaster Dynamic Precipitation Based on the HMS Model - Take Weihai as an Example. - Jinan University, Jinan.

[15] Liu, Z. Y., Yang, D. W., Hu, J. W. (2010): Dynamic Critical Rainfall-Based Torrential Flood Early Warning For Medium-Small Rivers. - Journal of Beijing Normal University (Natural Science) 3: 317-321.

[16] Ma, D. Z. (2017): Research on the Calculation Method of the Critical Rainfall of Flood Disaster in Hexi Inland River Basin. - Lanzhou University, Lanzhou.

[17] Mao, B. P. (2016): Application of the vertically-mixed runoff model to the calculation of the rainfall threshold of flash floods in ungauged basins. - Journal of Basic Science and Engineering 4: 720-730.

[18] Norbiato, D., Borga, M., Espost, S. D., Gaume, E., Anquetin, S. (2008): Flash flood warning based on rainfall thresholds and soil moisture conditions: An assessment for gauged and ungauged basins. - Journal of Hydrology 362(3-4): 274-290.

[19] Ren, C. F. (2015): Research on Early-Warning Indicators of Flash Flood Disaster in Small Watershed in Shandong Province and Its Application. - Shandong University, Jinan. 
[20] Sagar, R. C., Srinivas, V. V. (2015): Effect of DEM source on equivalent Horton-Strahler ratio based GIUH for catchments in two Indian river basins. - Journal of Hydrology 528: 463-489.

[21] Seo, D., Lakhankar, T., Mejia, J., Cosgrove, B., Khanbilvardi, R. (2013): Evaluation of operational National Weather Service gridded flash flood guidance over the Arkansas Red River Basin. - J Am Water Resour Assoc 49(6): 1296-1307.

[22] Tang, Y. P. (2017): Research on Critical Rainfall of A Flash Flood Disaster Based on Concentration model of GIUH-Case of Chenjiahe Watershed. - Xi'an University of Technology, Xi'an.

[23] Villarini, G., Krajewski, W. F., Ntelekos, A. A., Georgakakos, K. P., Smith, J. A. (2010): Towards probabilistic forecasting of flash floods: the combined effects of uncertainty in radar-rainfall and flash flood guidance. - Journal of Hydrology 394(1-2).

[24] Vizzari, D., Puntorieri, P., Praticò, F., Fiamma, V., Barbaro, G. (2018): Energy harvesting from solar and permeable pavements: a feasibility study. - Annales de Chimie - Science des Matériaux 42(4): 517-534.

[25] Wang, X. H., Wu, W., Tang, Y. P. Gong, L. Y., Ning, L. Z. (2018): Critical rainfall calculation based on R-V GIUH. - Journal of Northwest A \& F University (Natural Science Edition) 7: 147-154.

[26] Wen, K., Li, D. J., Jin, G. S. (1991): Mathematical Simulation of Surface Runoff Process. - Water Resources and Electric Power Press, Beijing, pp. 263-294.

[27] World Meteorological Organization (WMO) (1994): Guide to Hydrological Practices (WMO-No. 168). Fifth Ed. - WMO, Geneva, 2: 765.

[28] Ye, J. Y., Li, Z. J., Wu, Y. T. (2013): Study and application of flash flood warning method for ungauged basins. - Journal of Hydroelectric Engineering 3: 15-19, 33.

[29] Ye, J. Y., Li, Z. J., Chang, L. (2014): Research and application of flash flood early warning method based on dynamic critical precipitation. - Meteorological Monthly 40(1): 101-107.

[30] Zeng, X. Q., Zhen, Z. L., He, J. S., Han, L. X. (2018): A feature selection approach based on sensitivity of RBFNNs. - Neurocomputing 275: 2200-2208. 